\title{
AVALIAÇÃO DA ATRATIVIDADE DE DIFERENTES ISCAS AO \\ Rhynchophorus palmarum (COLEOPTERA: CURCULIONIDAE) NO CULTIVO DA PUPUNHEIRA (Bactris gasipaes)
}

SOLIMAN, Everton Pires ${ }^{1}$

GARCIA, Valéria Augusta ${ }^{2}$

PAVARINI, Ronaldo ${ }^{3}$

LIMA, Renata Cristina ${ }^{4}$

NOMURA, Edson Shigueaki ${ }^{2}$

PAVARINI, Gláucia Maria Pereira ${ }^{3}$

Recebido em: 2009. 12.28

Aprovado em: 2010.03.18

ISSUE DOI: $10.3738 / 1982.2278-350$

RESUMO: A pupunha (Bactris gasipaes) vem ganhando cada vez mais importância econômica para a região do Vale do Ribeira/SP. Poucos estudos são realizados com a cultura, porém sabe-se que um dos fatores limitantes ao seu cultivo esta associado à ocorrência de insetos praga, como a coleobroca Rhynchophorus palmarum. Suas larvas broqueiam o caule da planta podendo ocasionar perdas devido à redução do perfilhamento e abertura de ferimentos facilitando a ocorrência de doenças. Para o monitoramento de $R$. palmarum pode-se utilizar armadilhas do tipo balde contendo atrativos alimentares e feromônio sintético. $\mathrm{O}$ presente estudo visou avaliar diferentes atrativos em armadilhas tipo balde sobre a captura de adultos de $R$. palmarum. Foram testados cinco tratamentos compondo diferentes combinações de atrativos: feromônio, feromônio + toletes de cana-de-açúcar, toletes de cana-de-açúcar, feromônio + resíduo de pupunheira e resíduo de pupunheira somente. As armadilhas foram rotacionadas em cinco pontos da arena montada no campo. Por meio de avaliações semanais observou-se que o tratamento contendo resíduo de pupunha + feromônio foi o mais atrativo a broca.

Palavras-chave: Feromônio. Coleta missal. Amostragem.

\section{EVALUATION OF THE ATTRACTIVENESS OF DIFFERENT BAITS TO Rhynchophorus palmarum (COLEOPTERA: CURCULIONIDAE) AT PEACH PALM CULTIVATION (Bactris gasipaes)}

SUMMARY: The peach palm (Bactris gasipaes) has gained increasing economic importance to the region of Vale do Ribeira, SP. Few studies are conducted with this culture, but it is known that one of the limiting factors to its cultivation is associated with the occurrence of insect pests, such as palm weevil Rhynchophorus palmarum. Its larvae boring plant's stem may cause losses due to reduced tillering and opening holes that can serve as a gateway to pathogens. For management and monitoring of $R$ palmarum it can be used bucket traps containing different attractive foods and synthetic pheromone RMD1. This study aimed to evaluate different baits on the attractiveness of $R$. palmarum. Five treatments were studied: pheromone; pheromone and sugar cane stalks; sugar cane stalks; pheromone and peach palm residue and only peach palm residue. The traps were rotated at five points of the arena set up in the field. Weekly evaluations indicated that treatment that contained pheromone and peach palm residue was more attractive to the weevil, being greater than other treatments. Otherwise, traps containing only sugar cane stalks as baits were not attractive for this weevil.

Keywords: Pheromone; Massal collect; Sampling.

\footnotetext{
${ }^{1}$ Eng. Agr., Mestrando em Agronomia na FCA - UNESP de Botucatu

${ }^{2}$ Eng. Agr., Pesquisador (a) da APTA - Pólo Regional de Pariquera-Açu

${ }^{3}$ Eng. Agr., Docente da UNESP - Campus Experimental de Registro

${ }^{4}$ Eng. Agr. ex-aluna da UNESP - Campus Experimental de Registro
} 


\section{INTRODUÇÃO}

O palmito pode ser utilizado para consumo in natura e em conserva, sendo extraído de uma grande variedade de palmeiras, As palmeiras mais precoces e que produzem palmito de qualidade são preferidas pelos produtores, dentre elas destaca-se a pupunheira (BOVI, 1998).

Segundo Lorenzi (2002), a pupunheira pertence à família Palmae (Arecaceae) e pode ser encontrada desde a América Central até o norte da Bolívia e Brasil, adaptando-se a diferentes condições agroecológicas, pois tolera solos ácidos e de baixa fertilidade, porém precisam ser bem drenados.

A ocorrência de pragas na cultura corresponde a um dos fatores limitantes ao cultivo dessa palmácea. Bovi (1998) afirmou que Rhynchophorus palmarum trata-se de uma coleobroca que ataca a cultura da pupunheira na fase larval, podendo causar redução em sua produtividade por ocasionar redução do perfilhamento e abertura de orifícios que podem servir como porta de entrada a fitopatógenos.

Os adultos de $R$. palmarum são besouros negros de 45 a $60 \mathrm{~mm}$ de comprimento e de rostro desenvolvido. Os machos diferem das fêmeas por terem pêlos rígidos no lado dorsal do rostro. Cada fêmea põe cerca de 5 a 6 ovos por dia, perfazendo um total de até 250 ovos durante sua vida. As larvas são brancas, com cabeça marrom-escura e quando completamente desenvolvidas, podem atingir cerca de $70 \mathrm{~mm}$ de comprimento. A fase de pupa ocorre dentro de um casulo formado por fibras da própria planta (GALLO et al., 2002).

Villachica (1996) citado por Thomazini (2004) descreve que no cultivo do dendezeiro as plantas podem ser atacadas por $R$. palmarum, vetor do nematóide Rhadinaphelenchus cocophilus, causador da doença conhecida como "anel vermelho".

Esta espécie também ataca coqueiros, preferencialmente em decadência, cuja seiva em fermentação exala um odor que atrai os besouros, ocorrendo o mesmo com ferimentos produzidos em plantas sadias (GALLO et al, 2002). Já em pupunheiras, acontece de forma semelhante, porém o ataque ocorre, preferencialmente, na estipe onde foi efetuado o corte para colheita do palmito. Nesta região há fermentação da seiva, cujo odor atrai as coleobrocas, que irão efetuar sua postura.

Moura et al (1995) citaram que o uso simultâneo de iscas atrativas a base de toletes de cana-de-açúcar, plantas-armadilha, pulverização com inseticida na despalma e fomento de inimigos naturais reduziu progressivamente a população de $R$. palmarum numa área de dendezeiro e, conseqüentemente, declinou em $8,3 \%$ a mortalidade de plantas decorrente do ataque do nematóide causador do anel vermelho.

Não existe até o momento defensivos agrícolas registrados para a cultura da pupunha 
(AGROFIT, 2009) e por isto o estudo de métodos alternativos de monitoramento e controle desta praga é extremamente relevante para a cultura. O manejo com uso de feromônio juntamente com iscas atrativas visando a coleta massal da praga (GALLO, 2002; MOURA et al., 2006), está sendo incentivado junto aos produtores do Vale do Ribeira/SP como alternativa ao uso de inseticidas, além de ser uma técnica que não trás prejuízos ao meio ambiente.

Neste contexto realizou-se o presente trabalho objetivando estudar qual isca apresenta melhor atratividade a $R$. palmarum em armadilhas do tipo balde.

\section{MATERIAIS E MÉTODOS}

O trabalho baseou-se na captura de Rhynchophorus palmarum em área de cultivo comercial de pupunheira, localizada no município de Registro, sul do Estado de São Paulo. O experimento foi iniciado em janeiro de 2007, quando cinco armadilhas foram instaladas no campo. Estas armadilhas constaram de baldes plásticos com volume aproximado de 60 litros, com tampa perfurada por quatro orifícios equidistantes de aproximadamente duas polegadas de diâmetro, sendo que nestes orifícios foram conectados, internamente, por tubos de PVC de mesmo diâmetro, permitindo assim a entrada dos insetos e dificultando sua fuga.

Em cada armadilha foi utilizado um atrativo ou combinação de atrativos aos insetos, constituindo os tratamentos, sendo cada balde considerado uma repetição. Desta maneira montou-se um delineamento inteiramente casualizado com 5 repetições e 5 tratamentos a saber: toletes de cana-de-açúcar, toletes de cana-de-açúcar + feromônio, resíduo de pupunha, resíduo de pupunha + feromônio e feromônio somente.

Utilizou-se o feromônio RMD1 (6-Methyl-2(E)-hepten-4-ol, 2-Methyl-4-heptanol, 4Methyl-5-nonanol) na forma de sache liberador, perndurando o sache internamente na tampa do balde com auxílio de arame. Já nos tratamentos onde utilizou-se toletes de cana-de-açúcar ou resíduo da pupunheira, essas foram acondicionados no fundo da armadilha, sendo: seis toletes do colmo de cana-de-açúcar amassados (40 cm de comprimento) ou aproximadamente a mesma quantidade de resíduo do palmito de pupunheira.

O resíduo de palmito utilizado correspondeu aos restos que são descartados no momento da colheita e processamento do palmito, ou seja, bainha das folhas mais novas e parte da base do palmito (porção fibrosa destinada ao descarte).

As armadilhas foram dispostas em cinco pontos diferentes num esquema de arena em círculo com raio de $15 \mathrm{~m}$ e distanciadas $16 \mathrm{~m}$ entre si. As avaliações ocorreram semanalmente, durante cinco semanas e consistiu na contagem dos insetos, troca dos atrativos quando necessário e liberação dos insetos capturados no centro da arena. Cada armadilha 
permaneceu instalada uma semana em cada posição.

Não houve troca dos saches de feromônio ate o final do experimento. Os toletes de cana foram substituídos quinzenalmente e o resíduo de pupunha semanalmente. No momento da troca dos atrativos alimentares tomou-se o cuidado de não deixar o material na área, sendo este recolhido, ensacado e descartado distante da área experimental.

Dados de precipitação pluviométrica e temperatura durante a realização do experimento foram obtidos junto ao CIIAGRO (2008).

Os dados obtidos foram analisados pelo teste de Tukey a $0,05 \%$ de probabilidade.

\section{RESULTADOS E DISCUSSÃO}

Durante a realização do experimento foram observados valores de precipitação acumulada de $290,4 \mathrm{~mm}$, temperatura média máxima de $30,8^{\circ} \mathrm{C}$ e temperatura média mínima de $20,8^{\circ} \mathrm{C}$.

O número médio de insetos capturados nos diferentes tratamentos testados pode ser observado por meio da Figura 1. Percebe-se que quando se utilizou resíduo de pupunha + feromônio coletou-se em média 5,6 insetos, sendo este valor o maior dentre os tratamentos testados e diferentes estatisticamente dos valores observados nos outros tratamentos. O uso de toletes de cana ou de feromônio isoladamente mostrou-se ineficiente na coleta deste inseto.

Ferreira et al., (2001) citaram que a cana-de-açúcar é considerada a principal fonte alimentar para ser utilizada em armadilhas, combinada com o feromônio de agregação do $R$. palmarum. Citam ainda que outros materiais atrativos podem ser utilizados, como mamão, inhame, mandioca, casca de coco verde ou de abacaxi. Estas informações estão relacionadas ao cultivo do coqueiro ou do dendezeiro no nordeste do Brasil.

Moura et al. (2006), trabalhando em agroecossistemas do dendezeiro no estado da Bahia recomendam a utilização de toletes de cana amassados associados ao feromônio em armadilhas tipo balde para coleta de $R$. palmarum. A troca dos toletes de cana deve ser feita quinzenalmente, enquanto o sache liberador de feromônio deve ser trocado a cada 2 meses.

Santana (2008) também recomenda, como medida de controle de $R$. palmarum em cultivos de palmeiras para produção de palmito, o controle comportamental por meio do uso de armadilhas tipo balde associadas ao feromônio Rhyncoforol e toletes de cana-de-açúcar como atrativo alimentas.

O uso de toletes de cana + feromônio e resíduo de pupunha isoladamente apresentaram, em média, coleta aproximada de 2 insetos, valor este menor do que quando se utilizou resíduo de pupunha + feromônio. O uso de toletes de cana ou de feromônio 
isoladamente, praticamente não tiveram efeito atrativo sobre os insetos, não devendo ser utilizados desta maneira.

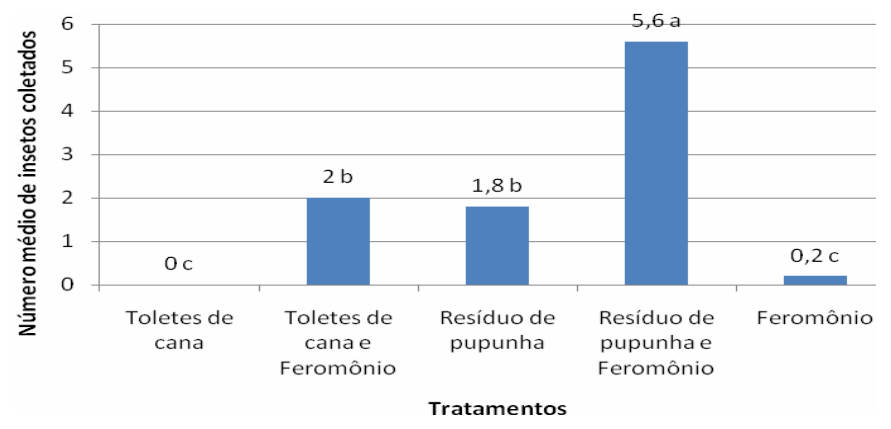

Figura 1. Número médio de $R$. palmarum capturados nos diferentes tratamentos. $\mathrm{F}=24,5^{* *}$ e $\mathrm{CV}=22 \%$ (análise com dados transformados pela raiz quadrada de y $+0,5-\operatorname{SQRT}(\mathrm{y}+$ $0,5)$ ). Letras diferentes na coluna diferiram entre si pelo teste de Tukey a $0,05 \%$ de probabilidade.

$\mathrm{Na}$ figura 2 estão representados os valores de coleta de insetos em cada data de avaliação. Verificou-se que o atrativo resíduo de pupunha + feromônio, além de ser o mais eficiênte na captura geral de $R$. palmarum, coletando $58.3 \%$ do total de insetos quantificados em todas as avaliações, manteve boa regularidade de captura durante o período analisado. Isto demonstra que esta combinação de atrativos teve efeito durante as cinco semanas de coleta, pois o sache do feromônio não foi substituído, havendo substituição quinzenal do resíduo de pupunha. A liberação de substâncias voláteis durante este período, proveniente da fermentação do resíduo de pupunheira juntamente com o feromônio, tiveram bom poder atrativo sobre os insetos.

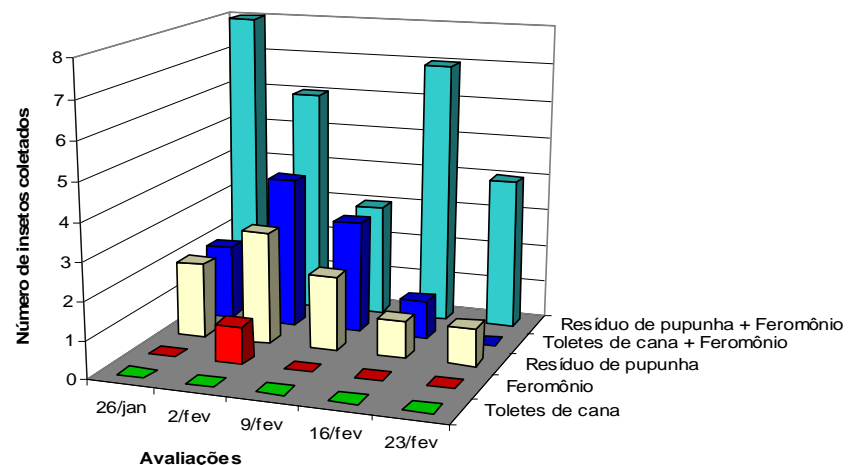

Figura 2. Número de insetos coletados em cada avaliação nos diferentes tratamentos.

Os tratamentos toletes de cana com feromônio, resíduo de pupunha, feromônio e somente toletes de cana coletaram 20,$8 ; 18,8 ; 2,1$ e $0 \%$, respectivamente.

A utilização de armadilha tipo balde com toletes de cana somente com atrativo, segundo Soliman et al. (2006), mostrou-se atrativa para duas coleobrocas da pupunheira, sendo que dentre o total de insetos coletados durante o período analisado Metamasius sp. correspondeu a 70,85\%, enquanto que $R$. palmarum correspondeu a $29,15 \%$ dos indivíduos coletados. Porém no presente estudo verificou-se que o tratamento contendo somente toletes 
de cana não apresentou atratividade.

No caso do cultivo da pupunha no sudeste do Brasil, principalmente na região do Vale do Ribeira em São Paulo, o resíduo gerado pela colheita do palmito é relativamente abundante e pode ser utilizado como fonte atrativa na coleta de $R$. palmarum, objetivando o monitoramento da praga como também seu controle por meio da coleta massal de insetos adultos.

\section{CONCLUSÃO}

Dentre as combinações testadas como atrativos para coleta de $R$. palmarum em armadilhas do tipo balde a utilização de resíduo de pupunha + feromônio mostrou-se como a mais eficiente.

\section{REFERÊNCIAS}

AGROFIT: sistema de agrotóxicos fitossanitários. Disponível em: http://extranet.agricultura.gov.br/agrofit cons/principal agrofit cons. Acesso em: 15 jun. 2007.

BOVI, M. L. A. Palmito pupunha: informações básicas para cultivo. Campinas: Instituto Agronômico, 1998. 50p. (Boletim Técnico 173)

FERREIRA J.M.S.; ARAÚJO, R.P.C.; SARRO, F.B. Armadilha Pet para captura de insetos adultos da broca-do-olho-do-coqueiro, Rhynchophorus palmarum. . Aracaju: Embrapa Tabuleiros Costeiros, 2001. 15p. (Circular Técnica, 22).

GALLO, D. et al. Manual de entomologia agrícola. v. 10. Piracicaba: FEALQ, 2002. 920p.

LORENZI, H. Árvores brasileiras: manual de identificação e cultivo de plantas arbóreas do Brasil. 4 ed. São Paulo: Instituto Plantarum, 2002. v.1.

MOURA, J.I.L. et al. Manejo integrado de Rhynchophorus palmarum L. no agroecossisetma do dendezeiro no Estado da Bahia. Jaboticabal: FUNEP, 2006. v.1. 60p.

MOURA, J.I.L.; RESENDE, M.L.B.; VILELA, E.F.; Manejo Integrado do Rynchophorus palmarum (L.) (Coleoptera: Curculionidae) em plantios de dendê na Bahia. In: SOCIEDADE ENTOMOLÓGICA DO BRASIL. Anais... Piracicaba, n.3, v.24, p.501-506, dez. 1995.

SANTANA, D.L.Q. Pragas potencias para as palmeiras com fins de produção de palmito. In: SANTOS, A.F.; CORRÊA JR., C.; NEVES, E.J.M. (editores). Palmeiras para a produção de palmito: juçara, pupunheira e palmeira real. Colombo: Embrapa Florestas, 2008.

SOLIMAN, E. P. et al. Ocorrência comparativa entre Rhyncophorus palmarum e Metamasius sp. coletados na cultura da pupunheira. In: CONGRESSO BRASILEIRO DE ENTOMOLOGIA, 21. Anais... 2006.

THOMAZINI, M.J. Ocorrência de Herminodes sp. (Lepidoptera: Noctuidae) em pupunheira nos Estados do Acre e Rondônia, Brasil. Acre: Embrapa, v. 34, n.3, p.505-506, 2004. Disponível em: http://acta.inpa.gov.br/fasciulos_base/34-3/html/BODY/v34n3a17.html Acesso em: 25 fev. 2007. 